\title{
COMPETITION, PREDATION, AND THE STRUCTURE OF THE AMBYSTOMA-RANA SYLVATICA COMMUNITY ${ }^{1}$
}

\author{
HENRY M. WILBUR \\ Society of Fellows and Museum of Zoology, University of Michigan, Ann Arbor 48104
}

\begin{abstract}
Populations of six species of amphibians were manipulated in field enclosures to study the biological tractability of current concepts of the organization of natural communities. Experimental communities with a known composition of mature eggs were introduced into screen enclosures in a pond to assay the importance of competition and predation to the ecology of amphibian larvae in temporary ponds. The competitive ability of each population was measured by its survivorship, mean length of its larval period, and mean weight at metamorphosis. Three simultaneous experiments (requiring 70 enclosures and 137 populations) were replicated in a randomized complete-block design for variance analysis.

The assumptions of the classical Lotka-Volterra model of competition were tested by raising Ambystoma laterale, Ambystoma tremblayi, and Ambystoma maculatum in all combinations of three initial densities $(0,32$, and 64$)$. All three measures of competitive ability were affected by competition with other species. Higher-order interactions decreased the variance of the outcomes of the experiments as species were added to the communities. The statistical effects of these higher-order interactions between the densities of competing species often exceeded the simple effects of competition. The increase in community stability with the addition of species to the community is not predicted by the classical models of community ecology.

The second experiment tested the effects of adjacent trophic levels on the structure of the three-species community. Eggs of Ambystoma tigrinum, a predator, and Rana sylvatica, an alternate prey of Ambystoma tigrinum, were added singly and together into systems with 16 eggs of species in the Maculatum species-group. Ambystoma tigrinum was a predator if it acquired an initial size advantage by preying on Rana sylvatica tadpoles; otherwise it was principally a competitor. Rana sylvatica adversely affected the Maculatum group by competing with invertebrate prey for periphyton and photoplankton. The three species in the Maculatum group had nearly the same response to the addition of both $A$. tigrinum and $R$. sylvatica.

Ambystoma texanum, which occurs sporadically in southern Michigan at the northern limit of its range but not on the study area, was introduced as a test for community saturation. Ambystoma texanum was successfully raised alone. When mixed with the Maculatum group, Ambystoma texanum had a low survivorship, a small body size, and a long larval period. The native species were affected equally by the introduction of Ambystoma texanum, demonstrating the complexity of the food web and the ecological pliability of salamander larvae.

The uncertainty of the temporary pond environment precludes extreme ecological specialization among these species of salamanders. Coexistence is a consequence of the relative advantages of the species in different years and the long adult life spans. The complexity of the food web and "predator switching" are probably important elements of the densitydependent interactions that contribute to the stability of communities within seasons.
\end{abstract}

The concept of the community has its historical roots in the thought of the seventeenth-century naturalists who recognized that species of plants and animals occurred in natural assemblages. The implications of this observation were slowly realized by natural historians. By the middle of this century, ecologists were discussing a theory of the community. Allee et al. (1949:436) defined the community as "a natural assemblage of organisms which, together with its habitat, has reached a survival level such that it is relatively independent of adjacent assemblages of equal rank; to this extent, given radiant energy, it is self-sustaining." Dice (1952) added that the community is the highest level at which life can be organized. Hence, it is in the context of the community that evolution occurs.

Recently ecologists have departed from the func-

${ }^{2}$ Received April 9, 1971; accepted November 18, 1971. tional definition of the community to a rather arbitrary concept that defines the community as the group of organisms being studied. Ecologists now study "grassland bird communities" (Cody 1968), "Drosophila communities" (Levins 1968), and "diatom communities" (Patrick 1968). The concept of the "community matrix" (Levins 1968, Vandermeer 1970 ) originally was restricted to groups of species that compete with one another.

My thesis is that these natural groupings of species are organized by interspecific interactions that can be discovered and evaluated by experimentally dissecting the community into smaller components. There is a large corpus of laboratory studies, beginning with those of Chapman (1928) and Gause (1934), that involved simple ecological communities with few interacting species. These simple communities are described satisfactorily by elementary 
mathematical models such as the logistic equation and its extensions. The logistic model proved inadequate as laboratory ecologists advanced from the protozoan systems of Gause (1934) to more-complex systems (Slobodkin 1953). For example, studies of flour beetles (Tribolium) required the addition of age structure (Park et al. 1965, Taylor 1968, Mertz 1969), genetic components (Lerner and Ho 1961; Dawson and Lerner 1962; Lerner and Dempster 1962; Park, Leslie, and Mertz 1964), and stochastic processes (Park 1954; Leslie and Gower 1958; Barnett 1962; Sokal and Huber 1963; Bartlett, Gower, and Leslie 1960; Leslie 1962; Niven 1967; Mertz and Davies 1968).

Most laboratory studies have considered only unstable associations in which one species always "wins" by driving the other to extinction. This tradition produced the "competitive exclusion principle," which was first suggested by Gause (1934:19, $45 \mathrm{f}$ ) and has even risen to the status of being called "Gause's axiom" (Slobodkin 1962). The period of coexistence can be prolonged by increasing the complexity of the environment (Huffaker 1958, predator-prey systems), or may be stabilized if each species has a refugium in which it has a competitive advantage (Frank 1957).

The observation that natural communities are diverse and stable for long periods of time poses the question of what limits the similarity of coexisting species. Many field ecologists have studied a sympatric pair of species with superficially similar ecologies, frequently congeners, by observing their feeding and microhabitat requirements until they discover "the differences that permit coexistence."

Ecologists have long realized the value of experimentation in the field (Clements and Weaver 1924, Gause 1936, Nicholson 1954, Murdoch 1970, St. Amant 1970), but there have been few well-designed experiments that used the theory and techniques of classical laboratory ecologists to assay the importance of competition and predation in the organization of natural communities. Connell (1961a), in a pioneering study, concluded that upper limits of intertidal invertebrates are set by physical factors, but that lower limits are set by biotic ones, such as competition for space. Eisenberg $(1966,1970)$ demonstrated that the availability of high-quality food may regulate the size of populations of the pond snail Lymnaea elodes. Paine $(1966,1969)$ demonstrated that a top predator (Pisaster) mediated competition for space among marine invertebrates. Wilbur (1971a) discussed the role of competition in maintaining the coexistence of the salamander $A \mathrm{~m}$ bystoma laterale and its sexual parasite, A. tremblayi.

My study uses an experimental approach to assay the importance of competition among three species of aquatic salamander larvae in the organization of temporary pond communities. The effect of a predator, and an alternate food source for the predator, on the structure of the community of smaller salamanders is examined. The community is tested for ecological saturation by adding a foreign species, which occurs south of the study area.

Most ecologists require a demonstration that a resource is in short supply before an interaction between species can be termed competitive (Milne 1961 ). The assumption that aquatic salamander populations are limited by their food supply has not been directly tested by manipulating the densities of prey populations. The examination of stomach contents (unpublished data) and the effect of population density on body size at metamorphosis support this assumption. A more operational description of the relationship between two species is to define the relationship as competition if the two species have adverse effects on one another, mutualism if both species have a positive effect on one another, and predation or parasitism (depending on the biology of the mechanism) if one species benefits from the association at the expense of the other species. This approach defines the relationship between two species by the sign of their interaction coefficients, which permits simple statistical tests for identifying relationships between species in communities.

The amphibian community of temporary ponds in southeastern Michigan consists of four salamanders of the genus Ambystoma and the frog Rana sylvatica. The genus Ambystoma contains four species groups. Three of the species used in the study: A. laterale, A. tremblayi, and A. maculatum, are in the Maculatum group, primarily an eastern group of woodland forms. The fourth species in the study area, A. tigrinum, is in the Tigrinum group. This group evolved in the American Southwest and invaded the northern part of its present range in the early Pliocene (Tihen 1958). The present distributions of the four species include an area of sympatry in northern Ohio and southern Michigan. The present amphibian fauna of Michigan has probably been stable for the last 4,000-5,000 years (Smith 1957, Zumberg and Potzer 1955). Within the area of sympatry, $A$. maculatum, $A$. laterale, and $A$. tremblayi and the frog Rana sylvatica frequently occur in the same ponds. A. tigrinum is often found alone. The literature of the natural histories of these species is reviewed in Wilbur $(1971 a, b)$.

\section{Methods and Materials}

The study was conducted on the University of Michigan's Edwin S. George Reserve, a 513-ha field station $7.2 \mathrm{~km}$ west of Pinckney in south-central Livingston County, Michigan. Extensive descriptions of the history and ecology of the Reserve can be 
found in Rogers (1942), Cantrall (1943), Cooper (1958), and Wilbur (1971b).

During 1970 field experiments were used to investigate the structure of the amphibian community in woodland ponds. All experiments were conducted in Burt Pond, a permanent pond near the center of the Reserve, which has been described by Young and Zimmerman (1956), Mitchell (1964), Botzler (1967), Brockelman (1969), and Wilbur (1971b). Burt Pond is surrounded by an oak-hickory woodlot except for the southeastern end, which opens into a tamarack bog. The pond receives water from a seepage area along its northern margin and from George Pond, a smaller pond about $100 \mathrm{~m}$ to the north. Burt Pond was dredged and dammed in 1942. The maximum depth is $1.25 \mathrm{~m}$, the surface area is $2,655 \mathrm{~m}^{2}$, and the volume is about $2,112 \mathrm{~m}^{3}$. The pond overflows in the early summer, but by late August the water has receded to expose a strip of rich muck about $3 \mathrm{~m}$ wide on the southern side and 1-2 $\mathrm{m}$ wide on the northern side. The $\mathrm{pH}$ is slightly acidic (6.46.8 ) in early May, but it becomes neutral by late June (Botzler 1967). Since 1963 the bottom of the permanent portions of the pond has been covered by a solid bed of Chara (Mitchell 1964). Predators that ambush prey (odonate naiads, Ranatra, Lethocerus, etc.) hunt in the Chara so that few areas of the pond are accessible only to swimming predators. The littoral areas have a mixture of Chara, Ceratophyllum, and Potamogeton berchtoldii and emergent vegetation of Leersia oryzoides, Sagittaria latifolia, and Eleocharis erythropoda. By mid-June about half of the surface is covered by Lemna minor and filamentous algae. This mat is shifted by the wind so that only the cove at the western end of the pond is constantly covered. The mat retains heat in the afternoon by buffering the effect of cooling winds (Young and Zimmerman 1956). Burt Pond supported populations of Lepomis macrochirus, Micropterus salmoides, and Pimephales notatus (R. M. Bailey, personal communication) until a winter kill in 1961-62 (Mitchell 1964). The highest trophic level is now composed of reptiles, amphibians, large insects, and leeches. During the summer of 1970 a large adult (carapace length of $30 \mathrm{~cm}$ ) and several juvenile Chelydra serpentina, an adult Natrix sipedon, and about 30 Chrysemys picta were resident. Carnivorous insects large enough to capture young $\mathrm{Am}$ bystoma larvae included Lethocerous americanus, Belostoma sp., Notonecta undulata, and Ranatra fusca. The leech Batrachbdella picta was a common parasite on both adults and larval Ambystoma. Other leeches in the pond include Macrobdella decora, Erpobdella punctata, Placobdella hollensis, $P$. parasitica, $P$. pappillifera, and Helobdella papillata (Sawyer 1968). The newt Notophthalmus viridescens is also common. The anuran fauna consists of large populations of Bufo americanus, Rana clamitans, and Hyla versicolor. Rana catesbiana and $R$. pipiens are present in low densities. There is a large population of Ambystoma tigrinum in the pond, which was estimated in June 1970 by Bailey's (1952) triple-catch method as 1,759 $\pm 1,500$ (SE) larvae. Larval $A$. laterale and $A$. tremblayi were occasionally taken. There are no records of $\boldsymbol{A}$. maculatum in the pond.

The experimental populations were retained in "pens" with external dimensions of 60 by 60 by $240 \mathrm{~cm}$ constructed with 5 by $5 \mathrm{~cm}$ fir frames and fiberglass window screening ( 7 meshes per $\mathrm{cm}$ ). Liđs were made of the same screening to exclude aerial predators. Kingfishers Megaceryle alcon and blackbirds, Quiscalus quiscula and Agelaius phoeniceus, forage along the pond margins, and raccoons Procycon lotor nightly patrol the edge of the pond. The pen bottoms were made of steel-reinforced plastic sheeting to provide a solid substrate. Some of these pens were also used by Brockelman (1969), Wilbur (1971a), and DeBenedictis (1970:11, see photograph). The screening excluded large invertebrate predators but permitted circulation of water and the entry of food species.

On May 2 and 3, 1970, all eggs of one species were mixed in two pans to assure a heterogeneous foundation for each experimental population. This mixing randomized both genetic effects and the dates of laying of the different clutches. The experimental populations were drawn from these mixtures and recounted before introduction into the pens. Each experimental treatment was represented once in each of two "blocks" of pens. Treatments were assigned to pens by a separate random procedure for each block. Each of the source ponds from which eggs were obtained contained all four species of $A m b y$ stoma and Rana sylvatica. The developmental stage of the stock at the time of introduction on May 4 varied from advanced tail-bud embryos to day-old hatchlings. All experiments were run simultaneously.

Each pen was examined for transformed juveniles every 2 days from 50 days after introduction of the populations (June 23) until day 70 (July 13), then every third day until day 173 (October 24). The pens were checked between 0600 and 0900 EST in order to capture the salamanders before they retreated to the water as the sun warmed boards, which had been placed at the inshore end of the pens on day 40 (June 13). All amphibians under the boards were collected. This ecological definition of metamorphosis is unambiguous and uses the same criterion for both frogs and salamanders. At metamorphosis salamanders have reduced gill stubs and the rudiments of adult pigmentation patterns; frogs have reduced tails. Both forms have suspended feeding.

Animals were identified and anesthetized in chloro- 
tone within an hour of capture. Salamanders from pens containing both $A$. laterale and $A$. tremblayi were identified by blood samples as described in Wilbur $(1971 b)$. The wet weight and body length of each animal were measured before it was fixed, individually tagged, and stored in formalin. The wet weights of towel-dried specimens were determined to $0.001-\mathrm{g}$ precision. Subsamples of each species were dried over silica gel at $35^{\circ}-45^{\circ} \mathrm{C}$ for 24 hours and then stored for an additional 24 hours over calcium chloride before weighing. This treatment assured a constant dry weight for even the largest specimens of $A$. tigrinum. All specimens are deposited in the amphibian collections of the University of Michigan Museum of Zoology. Listings of the composition of each population, the number of individuals that transformed, their body lengths, weights, and larval periods, and copies of all statistical analyses are in the library of the Division of Reptiles and Amphibians, Museum of Zoology.

Analysis of three simultaneous measures of competitive ability in systems with as many as five species is complex. One measure, survivorship, is a characteristic of the population. The other two measures, body weight and larval period, are characteristics of individuals. A reductionist approach was used in the analysis. First, single-species populations were examined, then all pairs of species, and finally the three-species communities were analyzed. Insight into the biological mechanisms regulating the community was obtained at each step of this progressive increase in the complexity of the analysis. Lewontin (1968) commented that this reductionist approach has been of paramount importance to molecular biologists but is virtually untouched by evolutionary ecologists. The assumptions of my approach are that the larval stage is the period in which the diversity of salamanders is regulated and that the most complex level of the analysis is a reasonable approximation of nature, which is tantamount to saying that the field enclosures and randomized design represent an adequate sample of the pond. However, as Gause (1934:120) warned, "we may be told that after we have 'snatched' two components out of a complex natural community and placed them under 'artificial' conditions we shall certainly not obtain anything valuable and shall come to absurd conclusions."

Each of the measures of competitive ability is assumed to be associated with Darwinian fitness, the expectation of the contribution of an individual to future generations. The demonstration of the relationship between these measures of competitive ability and the actual fitness would require following individual salamanders from the time of metamorphosis until at least their first breeding.

Most amphibians breed at a certain size rather than at a specific age (Tilley 1968). A large body size, relative to conspecifics, is assumed to be advantageous because it would increase the probability of breeding at an early age. In temporary pond habitats, an early metamorphosis is an escape from the invertebrate predators and parasites in the ponds. An early metamorphosis is also an escape from the increasing food shortage when prey populations crash during the summer as ponds shrink. In exceptionally wet years the ponds may retain water and support large populations of invertebrates throughout the summer. However, the annual rainfall in southern Michigan is virtually never greater than $125 \%$ of the average (Visher 1954). In the wet years it would be advantageous for salamanders to remain in the ponds if they are growing at a faster rate than they would in a terrestrial habitat (C. R. Shoop, personal communication). Survivorship per se is always advantageous, but it is a measure of the probability that a given individual in a population will live to metamorphosis.

The distributions of the lengths of the larval period and the body weights at metamorphosis were examined in each population. Tests of skewness and kurtosis were made on the larger samples. These two measures did not deviate significantly from normal distributions within populations. Within species the variances of body weights and larval periods were not correlated with the population means. Survivorship was always computed as the percentage of the individuals introduced that survived. This percentage survivorship was transformed to the arcsine of its square root for all parametric analyses (Bartlett 1947).

\section{Competition among the Maculatum SPECIES-GROUP}

The three species of the Maculatum group: $A$. laterale, $A$. tremblayi, and $A$. maculatum, were raised at all combinations of three initial densities of each species: 0,32 , and 64 . This $3 \times 3 \times 3$ factorial design for variance analysis has 26 treatments per replicate (the treatment of $0+0+0$ was not used). The treatments were randomly assigned to pens separately within each block. The full design included two replications of three species, each at three densities. The outcome was judged by three measures of competitive ability. The $3 \times 3 \times 3 \times 3 \times 2$ dimensionality of the data matrix is difficult to interpret. Therefore, a stepwise approach was used in the analysis. First, all pens that contained only one species were analyzed; within this analysis each measure of competitive ability was studied. Then all two-species systems were analyzed. Finally the pens with all three species were studied. Each of these analyses used separate portions of the data for independent comparisons of the species to determine the effect of increasing the complexity of the community. The re- 
TABle 1. Comparison of the species in the Maculatum group in single-species systems

\begin{tabular}{|c|c|c|c|c|c|c|}
\hline \multirow[b]{2}{*}{$\begin{array}{l}\text { Initial density per pen } \\
\text { Number survivors (both }\end{array}$} & \multicolumn{2}{|c|}{ A. laterale } & \multicolumn{2}{|c|}{ A. tremblayi } & \multicolumn{2}{|c|}{ A. maculatum } \\
\hline & 32 & 64 & 32 & 64 & 32 & 64 \\
\hline blocks) & 21 & 55 & 39 & 80 & 40 & 29 \\
\hline Percentage survivorship & $33 \%$ & $42 \%$ & $62 \%$ & $63 \%$ & $63 \%$ & $22 \%$ \\
\hline Mean body weight (g) & 0.940 & 0.639 & 0.792 & 0.774 & 0.989 & 1.054 \\
\hline \multicolumn{7}{|c|}{ Mean larval period (days } \\
\hline from hatching) & 87 & 94 & 81 & 92 & 95 & 91 \\
\hline
\end{tabular}

TABLE 2. Analysis of variance in body weight of Maculatum group in single-species systems

\begin{tabular}{lcccc}
\hline \hline Source & df & M.S.a & $F$ & $P$ \\
\hline Species differences & 2 & 1.335 & 15.837 & $<0.001$ \\
Density of conspecifics & 1 & 0.389 & 4.620 & $<0.050$ \\
Species X conspecifics & 2 & 0.595 & 7.061 & $<0.001$ \\
Error & 258 & 0.084 & &
\end{tabular}

a Mean square.

sults from the two blocks were always pooled before the analysis to avoid missing values in four of the three-species treatments, which had no survivors of one of the species in one replicate.

\section{Single-species systems}

Four pens for each species were used at the first level of the analysis. Within each of the two blocks the species were raised alone at initial densities of 32 and 64 . The data for all three species (12 pens) were used in the analysis of each measure of competitive ability. Table 1 compares the survivorship, mean body weight at metamorphosis, and the mean length of the larval period of each species. This analysis used a $3 \times 2$ factorial design with unequal subclass numbers to test the effects of species differences, the density of conspecifics, and the interaction between these two main effects.

The greatest difference between the species is the body weight at metamorphosis (Table 2). The order of the species by increasing body sizes at the low density was $A$. tremblayi, $A$. laterale, and $A$. maculatum, but at the high density the order was $A$. laterale, $A$. tremblayi, then $A$. maculatum. This resulted from the strong response of $A$. laterale to the density of conspecifics.

The length of the larval period was analyzed with the same design as for the body weight analysis. The only significant term was the interaction between the species difference and the density of conspecifics $\left(F_{2,258}=3.652, P<0.05\right)$. The order of the species, with respect to increasing length of larval period, was $A$. tremblayi, $A$. laterale, and $A$. maculatum at the low density, and $A$. maculatum, $A$. tremblayi, then $A$. laterale at the high density. $A$. tremblayi had the strongest response to density- the first suggestion of a difference in adaptations for competition among the species.

The analysis of variance of the survivorship data used the transformed survivorship of each population from the date of introduction until metamorphosis. The observations from each block were treated at replicate observations in a $3 \times 3$ factorial design for variance analysis. There were no significant effects in this analysis.

In summary, the three species reacted differently to an increase in the density of conspecifics. Ambystoma laterale increased both the number of survivors and the percentage survivorship when the density of conspecifics was increased. Presumably, this was accomplished by dividing the available food among smaller larvae and by increasing the mean larval period. The response of $A$. tremblayi was similar. An increase in density resulted in a higher number of survivors (but not a significantly higher survivorship), but each animal was smaller and required a longer time to reach metamorphosis. The plastic growth rate and variable size at metamorphosis of these species are adaptations to the uncertain environment of temporary ponds. Ambystoma maculatum is less plastic. At the high density only a few larvae survived, but they were large and had a relatively rapid larval period. This suggests that the effect of larval density occurred early in the season. The few larvae that survived this competition were able to exploit the food supply and rapidly grow to a large size.

\section{Two-species systems}

A second set of pens contained all possible pairs of species, each at an initial density of 32 or 64 . These populations were analyzed by a $2 \times 2 \times 2$ factorial analysis of variance in which the factors and levels were: species (e.g., $A$. laterale and $A$. tremblayi), density of species A ( 32 or 64), and density of species B ( 32 or 64 ). The eight treatment combinations for each pair of species were represented once in each block. The results from the two blocks were pooled before the analysis.

\section{A. laterale and A. tremblayi}

In the absence of $A$. maculatum, the eight systems with $A$. laterale and $A$. tremblayi had a final mean composition of $21 \mathrm{~A}$. laterale and $17 \mathrm{~A}$. tremblayi. The variance (the mean square of the Euclidean distances from the final compositions to the mean final composition) around this mean was 76. Lewontin (1969) has borrowed the term "temperature" from statistical mechanics to describe this variance. This term will only cause confusion if it is used in a biological context-"the temperature of the system varied with the temperature of the environment"so I will use "mean square" or "variance" to de- 
Table 3. Two-species systems of Ambystoma laterale and A. tremblayi: data summary

\begin{tabular}{|c|c|c|c|c|c|c|}
\hline Species & A. laterale & $\begin{array}{l}\text { per pen } \\
\text { A. tremblayi }\end{array}$ & $\begin{array}{l}\text { Number of } \\
\text { survivors } \\
\text { (both blocks) }\end{array}$ & $\begin{array}{c}\text { Percentage } \\
\text { survivorship }\end{array}$ & $\begin{array}{l}\text { Mean } \\
\text { larval } \\
\text { period } \\
\text { (days) }\end{array}$ & $\begin{array}{c}\text { Mean } \\
\text { body } \\
\text { weight } \\
\text { (g) }\end{array}$ \\
\hline \multirow{4}{*}{ A. laterale } & \multirow{2}{*}{32} & 32 & 37 & $58 \%$ & 98 & 0.608 \\
\hline & & 64 & 60 & $97 \%$ & 98 & 0.556 \\
\hline & \multirow{2}{*}{64} & 32 & 46 & $28 \%$ & 88 & 0.518 \\
\hline & & 64 & 31 & $24 \%$ & 100 & 0.573 \\
\hline \multirow{4}{*}{ A. tremblayi } & \multirow{2}{*}{32} & 32 & 32 & $48 \%$ & 91 & 0.724 \\
\hline & & 64 & 61 & $48 \%$ & 84 & 0.612 \\
\hline & \multirow{2}{*}{64} & 32 & 22 & $34 \%$ & 82 & 0.732 \\
\hline & & 64 & 31 & $24 \%$ & 99 & 0.630 \\
\hline
\end{tabular}

scribe the scatter in the final outcomes. The significance of this outcome is tested by the analysis of variance in the survivorships. The variance between replicates was large enough to obscure differences between all treatment effects; an exception was the effect of the density of $A$. laterale, which caused a strong decrease in the survivorship of both species $\left(F_{1,8}=8.900, P<0.05\right)$.

The length of the larval period (Table 3) of $A$. laterale was significantly longer than that of $A$. tremblayi in all treatment combinations $\left(F_{1,311}=\right.$ $7.148, P<0.01)$. The highly significant interaction between the densities of the two species $\left(F_{1,311}=\right.$ 10.660, $P<0.005$ ) resulted from a much stronger response to increases in the density of competitors when the density of conspecifics was also high. This nonlinear response to density will be discussed in a later section.

The mean body weight at metamorphosis was a sensitive measure of the effect of competition (Table $3)$. The difference between the species was highly significant (Table 4). Both species reduced their body size when in competition with either conspecifics or with the other species. At all treatment levels $A$. tremblayi had a larger body weight at metamorphosis. At a low density of conspecifics $A$. laterale was strongly affected by $A$. tremblayi, whereas the effect of $A$. laterale on $A$. tremblayi was about the same at both densities of conspecifics.

In summary, the three measures of competition reflect the species differences that were evident in the single-species systems. In general, these differences were intensified by competition. The divergence was most evident with the addition of competitors at the lower densities of conspecifics.

\section{A. laterale and A. maculatum}

The eight systems of $A$. laterale and $A$. maculatum tended toward a final composition of $21 \mathrm{~A}$.
Table 4. Analysis of variance of body weight of $A m b y$ stoma laterale and $A$. tremblay $i$ in two-species systems

\begin{tabular}{lccrcc}
\hline \hline \multicolumn{1}{c}{ Source } & df & M.S. & \multicolumn{1}{c}{$F$} & \multicolumn{1}{c}{$P$} \\
\hline Species differences & 1 & 0.882 & 38.121 & $<0.005$ \\
Density of $A$. laterale & 1 & 0.010 & 0.445 & \\
Density of $A$. tremblayi & 1 & 0.198 & 8.567 & $<0.005$ \\
Species X $A$. laterale & 1 & 0.044 & 1.915 & \\
Species X $A$. tremblayi & 1 & 0.210 & 9.069 & $<0.005$ \\
A. laterale X A. tremblayi & 1 & 0.061 & 2.633 & \\
3-way interaction & 1 & 0.042 & 1.798 & \\
Error & 311 & 0.023 & & \\
& & & & & \\
\hline
\end{tabular}

laterale and $16 \mathrm{~A}$. maculatum. This poorly defined cluster had a mean square of 69 . The analysis of variance of survivorship had no significant terms, a reflection of the high variance between replicates.

In contrast to survivorship, the length of the larval period and the body weight at metamorphosis are sensitive measures of competition (Table 5). Ambystoma maculatum had a longer larval period, especially at the low density of conspecifics. The mean square of the interaction between the species differences and the density of $A$. maculatum was greater than the mean square of either of the main effects (Table 6). This result is evidence for the importance of density-dependent competition coefficients in the system. An increase in the density of conspecifics increased the length of the larval period of $A$. laterale, but it had a mixed effect on $A$. maculatum. Ambystoma maculatum was more sensitive to competition with $A$. laterale at the low density of conspecifics. Ambystoma laterale was affected more strongly by $A$. maculatum at the high density of conspecifics.

These results are confirmed by the analysis of body weight (Tables 5 and 6). Ambystoma maculatum has a larger body size. Both species have a strong effect on the other species, but there is not usually a strong divergence in the characteristics of $\boldsymbol{A}$. late- 
TABLE 5. Two-species systems of Ambystoma laterale and A. maculatum: data summary

\begin{tabular}{|c|c|c|c|c|c|c|}
\hline Species & $\begin{array}{l}\text { Initial de } \\
\text { A. laterale }\end{array}$ & $\begin{array}{l}\text { per pen } \\
\text { A. maculatum }\end{array}$ & $\begin{array}{l}\text { Number of } \\
\text { survivors } \\
\text { (both blocks) }\end{array}$ & $\begin{array}{l}\text { Percentage } \\
\text { survivorship }\end{array}$ & $\begin{array}{l}\text { Mean } \\
\text { larval } \\
\text { period } \\
\text { (days) }\end{array}$ & $\begin{array}{c}\text { Mean } \\
\text { body } \\
\text { weight } \\
\text { (g) }\end{array}$ \\
\hline \multirow{4}{*}{ A. laterale } & \multirow{2}{*}{32} & 32 & 40 & $62 \%$ & 91 & 0.589 \\
\hline & & 64 & 26 & $39 \%$ & 88 & 0.766 \\
\hline & \multirow{2}{*}{64} & 32 & 67 & $52 \%$ & 102 & 0.484 \\
\hline & & 64 & 33 & $26 \%$ & 117 & 0.473 \\
\hline \multirow{4}{*}{ A. maculatum } & \multirow{2}{*}{32} & 32 & 15 & $24 \%$ & 125 & 0.614 \\
\hline & & 64 & 40 & $31 \%$ & 105 & 1.119 \\
\hline & \multirow{2}{*}{64} & 32 & 34 & $53 \%$ & 91 & 0.734 \\
\hline & & 64 & 41 & $29 \%$ & 112 & 0.681 \\
\hline
\end{tabular}

TABLE 6. Analyses of variance of larval period and body weight of Ambystoma laterale and A. maculatum in twospecies systems

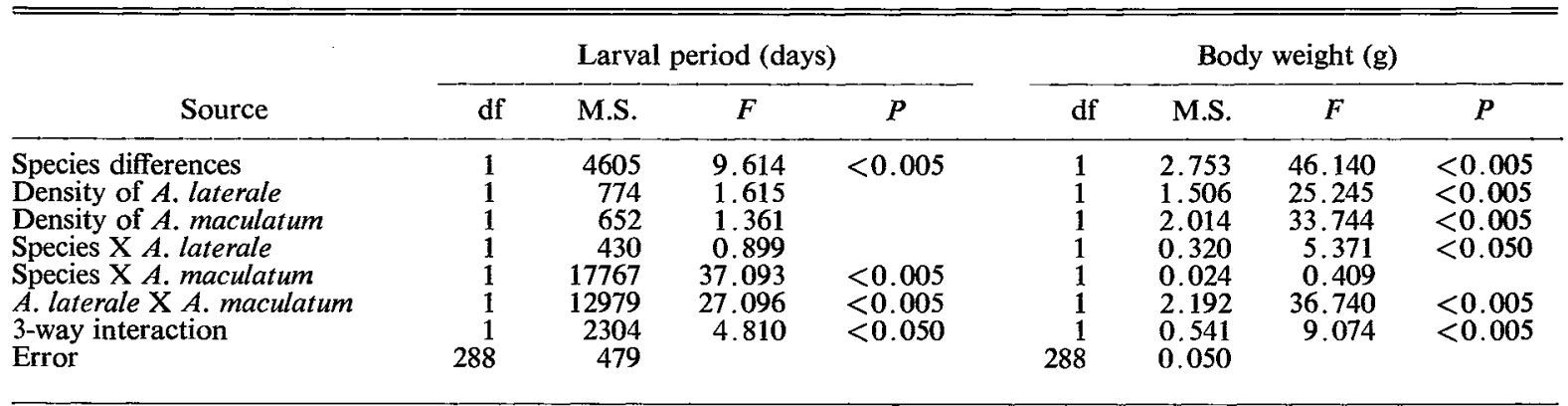

rale and $A$. maculatum when in competition, compared to when they are in single-species populations. As in the analysis of larval period, there is a highly significant interaction between the densities of the two species.

\section{Ambystoma tremblayi and $A$. maculatum}

The eight systems with only $A$. tremblayi and $A$. maculatum had a mean outcome of $18 A$. tremblayi and $20 \mathrm{~A}$. maculatum. The mean square was 70 , which was due as much to differences within treatments as between treatments.

Ambystoma maculatum had a significantly longer larval period than $A$. tremblayi (Tables 7 and 8 ). Both species increased the length of their larval period at high densities of either conspecifics or competitors. The two species reacted differently to increases in the density of $A$. maculatum. Ambystoma tremblayi was less affected than $A$. maculatum.

The results of the analysis of body weight are similar to those for the analysis of the length of the larval period (Tables 7 and 8). Ambystoma maculatum had a significantly larger body size and a stronger response to an increase in the density of conspecifics. Both species decreased their body size in the presence of competition, but the significant interactions between the densities of the two species and the differences between species confuses the analysis.

Ambystoma tremblayi and $A$. maculatum are significantly different with respect to their body weights and the lengths of their larval periods, but they respond to density in similar ways. There is no evidence for divergence in the characteristics of the two species together compared to when they are in singlespecies populations.

In summary, the analyses of each pair of species have shown that differences between species have been maintained or even magnified by competition. Each species competes significantly with all other species and, in most cases, the first-order interaction coefficients are not constants but functions of density.

\section{Three-species systems}

The third set of pens initially contained either 32 or 64 individuals of each species. In several of the pens either one or two of the species were eliminated; this result was considered a valid experimental outcome. The eight treatment combinations were repli- 
TABLE 7. Two-species systems of Ambystoma tremblayi and A. maculatum: data summary

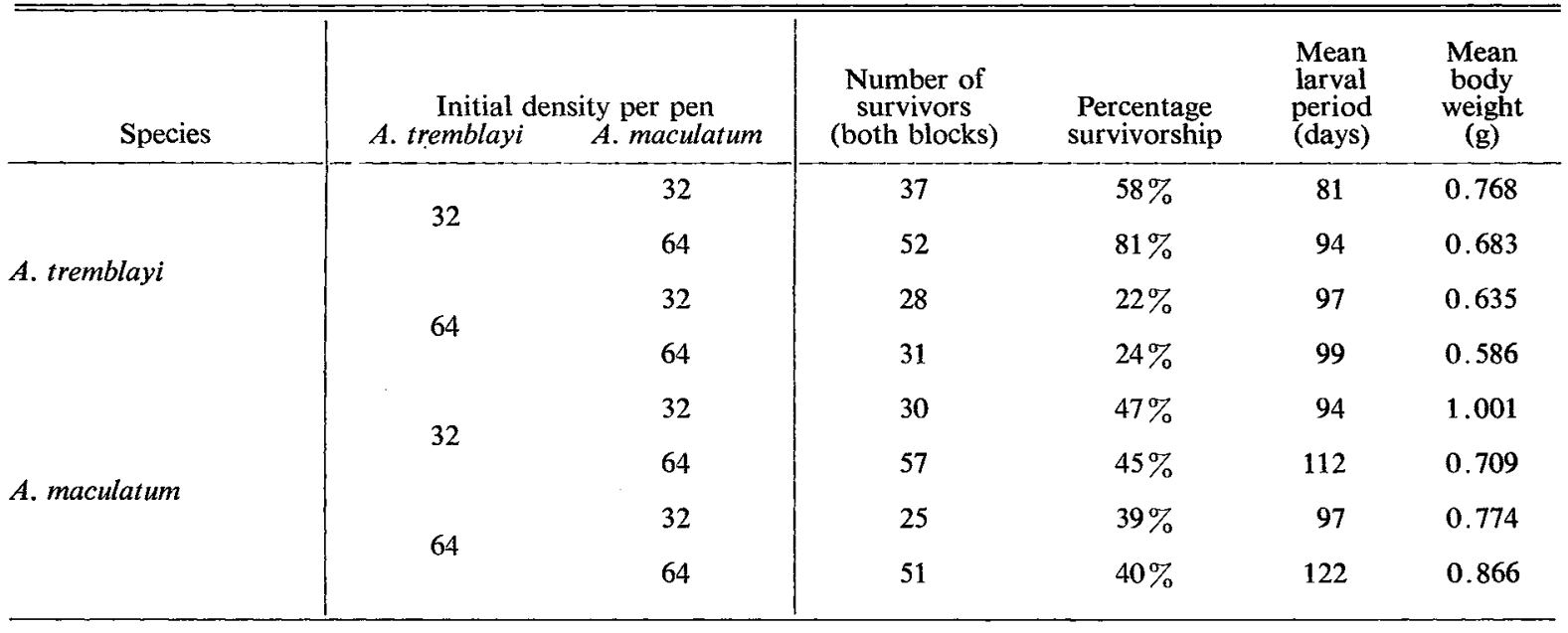

TABle 8. Analyses of variance of larval period and body weight of Ambystoma tremblayi and $A$. maculatum in two-species systems

\begin{tabular}{|c|c|c|c|c|c|c|c|c|}
\hline \multirow[b]{2}{*}{ Source } & \multicolumn{4}{|c|}{ Larval period (days) } & \multicolumn{4}{|c|}{ Body weight (g) } \\
\hline & $\mathrm{df}$ & M.S. & $F$ & $P$ & df & M.S. & $F$ & $P$ \\
\hline Species differences & 1 & 13549 & 19.071 & $<0.005$ & 1 & 2.048 & 54.683 & $<0.005$ \\
\hline Density of $A$. tremblayi & 1 & 5409 & 7.613 & $<0.010$ & 1 & 0.403 & 10.764 & $<0.005$ \\
\hline Density of $A$. maculatum & 1 & 15132 & 21.298 & $<0.005$ & 1 & 0.496 & 13.237 & $<0.005$ \\
\hline Species X A. tremblayi & 1 & 297 & 0.418 & & 1 & 0.111 & 2.968 & \\
\hline Species X A. maculatum & 1 & 3737 & 5.261 & $<0.050$ & 1 & 0.019 & 0.519 & \\
\hline A. tremblayi X A. maculatum & 1 & 33 & 0.047 & & 1 & 0.789 & 21.068 & $<0.005$ \\
\hline 3-way interaction & 1 & 1641 & 2.310 & & 1 & 0.536 & 14.309 & $<0.005$ \\
\hline Error & 303 & 710 & & & 303 & 0.037 & 14.005 & \\
\hline
\end{tabular}

cated in each block, but the results were pooled before the analysis. Since each species was represented at least once for each treatment combination, the pooling of replicates circumvented the need for specific techniques to evaluate the designs with missing cells and permitted a direct comparison between the analyses of all levels of complexity. Again, the following analyses are based only on the pens that initially contained all three species; therefore, the results are statistically independent of the singlespecies and two-species systems. But the experimental error and environmental component of variation are the same for all levels of the analysis because all pens were randomized together within the blocks.

The final outcomes of the 16 three-species systems have a center at $12 A$. laterale, $17 A$. tremblay $i$, and $11 \mathrm{~A}$. maculatum. The mean square of this cluster is 36. As in the two-species systems, the variance between replicates was high. The sole significant term in the analysis of variance of survivorship is the interaction between the density of $A$. laterale and the density of $A$. maculatum $\left(F_{1,24}=3.604, P<0.05\right)$, which is due to the high survivorship of $A$. laterale and $A$. tremblay $i$ in the pens with $32 A$. laterale and $32 A$. maculatum regardless of the density of $A$. tremblayi. The mechanism of this result is not obvious; probably little biological significance should be attached to this inconsistent result among the 45 comparisons that were made.

The mean lengths of the larval periods of the three species (Table 9$)$ were significantly different $\left(F_{2,524}\right.$ $=12.755, P<0.001$ ), as expected from the analyses of the two-species systems. The order of the species according to the lengths of their larval periods is also predicted: $A$. tremblayi, $A$. laterale, and $A$. maculatum. As the density of $A$. maculatum increased, $A$. laterale and $A$. tremblayi lengthened their larval periods $\left(F_{1,524}=4.970, P<0.05\right)$. But A. maculatum was not significantly affected by its own density.

The body weight at metamorphosis was a more sensitive measure of the effect of competition (Table 9). Again species were significantly different (Table 10); $A$. laterale was smaller than $A$. tremblayi, and both were smaller than $A$. maculatum. The densities of $A$. laterale and $A$. tremblayi significantly affected the system both as main effects and in their interaction at the low density of $A$. laterale. A mbystoma maculatum was important in the system only through its interaction with $A$. laterale and $A$. tremblayi. The 
"TABLE 9. Three-species systems of the Maculatum group: data summary

\begin{tabular}{|c|c|c|c|c|c|c|c|c|c|c|c|}
\hline \multicolumn{3}{|c|}{ Initial density of competitors } & \multicolumn{3}{|c|}{ Percentage survivorship } & \multicolumn{3}{|c|}{$\begin{array}{c}\text { Mean } \\
\text { larval period (days) }\end{array}$} & \multicolumn{3}{|c|}{$\begin{array}{c}\text { Mean } \\
\text { body weight (g) }\end{array}$} \\
\hline A. laterale & A. tremblayi & A. maculatum & A.l. & A.t. & A.m. & A.l. & A.t. & A.m. & A.l. & A.t. & A.m. \\
\hline \multirow{4}{*}{32} & \multirow{2}{*}{32} & 32 & $34 \%$ & $42 \%$ & $14 \%$ & 97 & 78 & 98 & 0.686 & 0.652 & 0.972 \\
\hline & & 64 & $17 \%$ & $21 \%$ & $9 \%$ & 92 & 90 & 98 & 0.817 & 0.866 & 0.972 \\
\hline & \multirow{2}{*}{64} & 32 & $44 \%$ & $59 \%$ & $24 \%$ & 97 & 78 & 110 & 0.575 & 0.596 & 0.854 \\
\hline & & 64 & $7 \%$ & $14 \%$ & $8 \%$ & 95 & 90 & 110 & 0.411 & 0.428 & 0.968 \\
\hline \multirow{4}{*}{64} & \multirow{2}{*}{32} & 32 & $41 \%$ & $19 \%$ & $1 \%$ & 89 & 83 & 108 & 0.494 & 0.685 & 0.807 \\
\hline & & 64 & $42 \%$ & $7 \%$ & $51 \%$ & 104 & 105 & 107 & 0.606 & 0.634 & 0.762 \\
\hline & \multirow{2}{*}{64} & 32 & $34 \%$ & $21 \%$ & $6 \%$ & 99 & 88 & 100 & 0.697 & 0.647 & 0.821 \\
\hline & & 64 & $6 \%$ & $10 \%$ & $13 \%$ & 111 & 95 & 109 & 0.415 & 0.479 & 0.658 \\
\hline \multicolumn{3}{|l|}{ Grand means } & 26 & 22 & 13 & 98 & 88 & 105 & 0.587 & 0.623 & 0.851 \\
\hline
\end{tabular}

TABLE 10. Analysis of variance of body weight of the Maculatum group in three-species systems

\begin{tabular}{|c|c|c|c|c|}
\hline Source & df & M.S. & $F$ & $\boldsymbol{P}$ \\
\hline Species"differences & 2 & 1.112 & 26.742 & $<0.001$ \\
\hline Density of $A$. laterale & 1 & 0.497 & 11.953 & $<0.001$ \\
\hline Density of $A$. tremblayi & 1 & 0.820 & 19.731 & $<0.001$ \\
\hline Density of $A$. maculatum & 1 & 0.091 & 2.191 & \\
\hline A. laterale $\mathrm{X}$ A. tremblayi & 1 & 0.309 & 7.436 & $<0.010$ \\
\hline A. laterale X A. maculatum & 1 & 0.219 & 5.257 & $<0.050$ \\
\hline A. tremblayi $\times$ A. maculatum & 1 & 0.591 & 14.227 & $<0.001$ \\
\hline Species $1 \times$ A. laterale & 2 & 0.100 & 2.414 & \\
\hline Species X A. tremblayi & 2 & 0.063 & 1.518 & \\
\hline Species X A. maculatum & 2 & 0.003 & 0.071 & \\
\hline Sp. XIA. lat. X A. trem. & 2 & 0.072 & 1.737 & \\
\hline Sp. X A. lat. X A. mac. & 2 & 0.014 & 0.338 & \\
\hline Sp. X A. trem. X A. mac. & 2 & 0.117 & 2.822 & \\
\hline A. lat. $\times$ A. trem. $\times$ A. mac. & 1 & 0.002 & 0.045 & \\
\hline 4-way interaction & 2 & 0.114 & 2.735 & \\
\hline Error & 524 & 0.042 & & \\
\hline
\end{tabular}

insignificance of the interactions involving species differences implies that there are no strong differences in the effect of one species on another. The significant two-way interactions between each pair of species in the system implies that competition is a function of the total number of salamanders in the system, and is not greatly influenced by the initial configuration of the system (e.g., 32-32-64, 32-64. 32 , or $64-32-32$ ). This result is consistent with the strong similarity of the ecologies of the three species.

\section{Community complexity and stability}

The value of the stepwise approach is two-fold: by proceeding from the simple to the complex, intuition is accumulated that can be used to suggest mechanisms that integrate the whole community. We can further ask if the three-species system has emergent properties that could not be predicted from separate analyses of the subsystems. For example, in proceeding from the one-species to the two-species systems, the effects of species were not additive. The impact of a competing species depended on the density of conspecifics. The importance of this nonlinearity was measured by the interaction between the density of conspecifics and the density of competitors in the analyses of variance (Tables $2,4,6$, $8,10)$. Response surfaces were construced from the data for the complete design (Fig. 1). These surfaces display the interactions between the densities of competing species. The systems without significant interaction terms have smooth responses to density. For example, $A$. tremblayi has an even response in body weight to increasing densities of both $A$. laterale and $A$. maculatum. The response to $A$. maculatum is greater as shown by the relative slope of the surface. But $A$. laterale has an uneven response to the density of the other species. As the densities are increased from 0 to 32 there is a sharp decrease in the body weight of $A$. laterale in the low-density pens. An addition of 32 more larvae of either species does not have a striking effect; but, if the densities of both species are increased to 64 , there is another sharp reduction in the body size of the $32 \mathrm{~A}$. laterale. This is the kind of interaction that contributed to the $A$. tremblayi X $A$. maculaum interaction in Table 5 . The response of the low-density population of $A$. laterale was different from the response of the highdensity population. This is the kind of difference that contributed to the $A$. laterale $\mathrm{X} A$. tremblay $i$ and $A$. laterale $\mathrm{X} A$. maculatum components of Table 5. The species $\mathrm{X} A$. maculatum interaction resulted from differences such as the contrast between the response of $A$. laterale and the response of $A$. tremblayi to the same increases in the density of $A$. maculatum. The highly significant interactions cause twisted and folded surfaces, such as the $A$. maculatum body-weight diagrams.

These nonlinearities can also be examined by analyzing the trajectories of the species compositions 

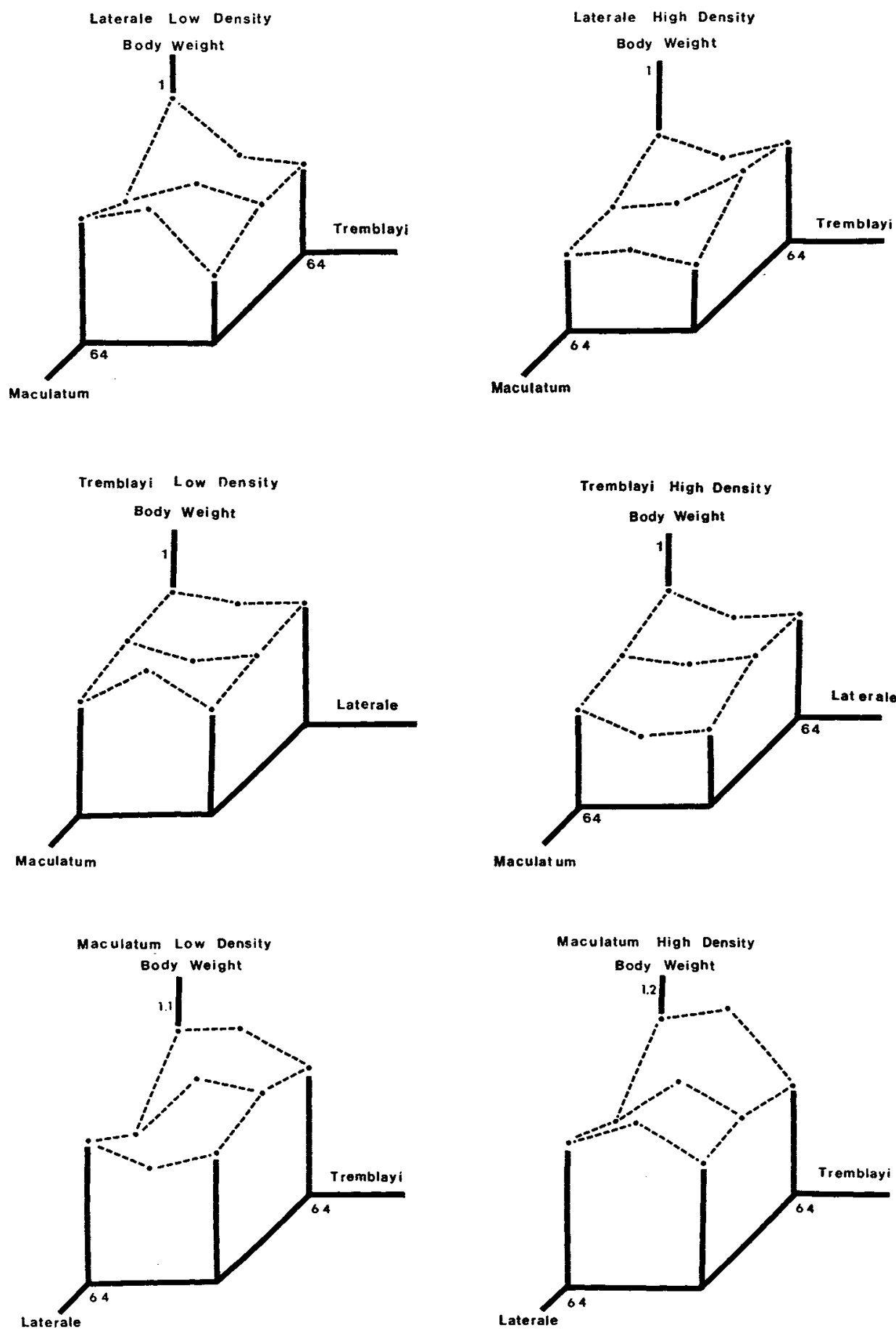

FIg. 1. Body-weight response surface for full design. Vertical axes represent mean body weights (grams) of all survivors in both replicate populations of species with low (32) or high (64) initial densities. The horizontal axes are the densities of competing species $(0,32$, or 64). Smooth surfaces indicate additive interaction coefficients; complex surfaces indicate density-dependent responses. The relative amount of competition between species is measured by the symmetry of the surfaces. 
of the systems from the start to the conclusion of the experiment. The trajectories of the systems demonstrated a tendency to converge on a mean composition. A linear relationship between the mean squares of the final states of the systems and the number of species in the systems is expected if the effects of species on each other are additive. Because the mean square is the sum of the Euclidean distances of each pen's composition to the mean composition, by definition the mean square $v^{2}$ is

$$
v^{2}=(1 /[N-1]) \sum_{j=1}^{S} \sum_{i=1}^{N}\left(\bar{x}_{j}-X_{i j}\right)^{2}
$$

in which $\bar{x}_{j}$ is the mean size of the population of species $j, S$ is the number of species in the community, and $N$ is the number of experimental systems. In Fig. 2 the mean squares of all systems are plotted against the number of species in the communities. There is a point for each species raised alone $(N=4)$, a point for each pair of species $(N=8)$, and a point for all three-species systems $(N=16)$. By inspection the curve is decreasing. The three-species systems have a lower observed mean square than would be expected from the lower-order systems. This conclusion is robust due to the increased degrees of freedom associated with each point, a consequence of the factorial property of the experimental design.

Frequently the higher-order interactions are as important as the main effects. This result means that competition among salamander larvae is not a simple additive process that is a function of the total number of larvae in the community, but it is a complex

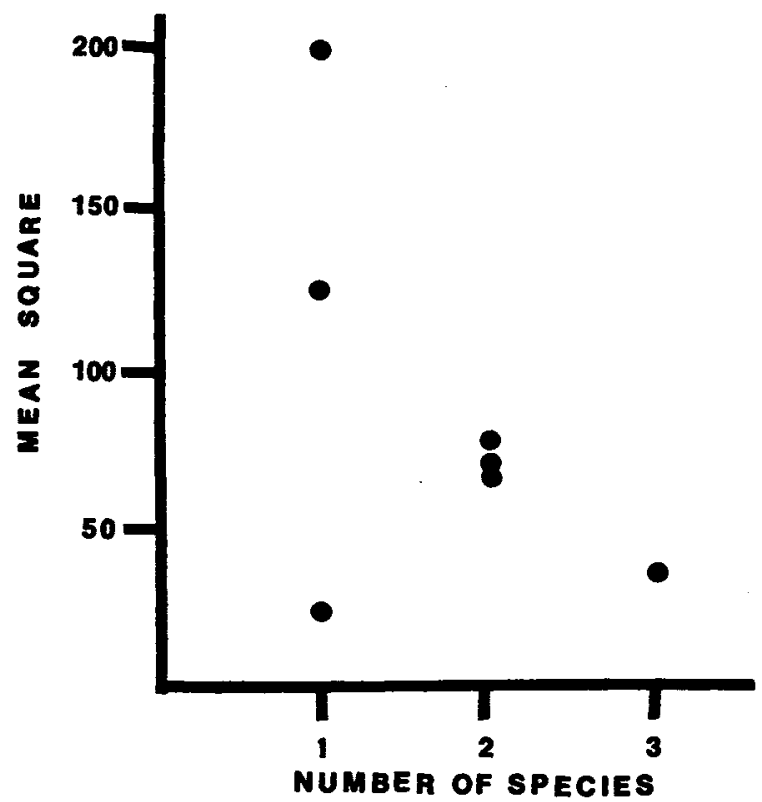

FIG. 2. Relationship between the mean square of the final compositions and the number of species in the systems. interaction between the proportions as well as the abundances and identity of the species.

The relationship between complexity and stability has been discussed but rarely demonstrated in ecology (MacArthur 1955; Odum 1959, 1962; Leigh 1965). Hairston et al. (1969) found no relationship between diversity and stability within trophic levels of bacteria-protozoa systems. The relationship between climatic stability and tropical diversity has been widely discussed (see review by Pianka 1966), but the evidence for a return to a steady state after perturbations is scant. The salamander community is highly interactive, making the outcome of complex communities less variable than the outcome of simple communities.

\section{The Role of Predation}

Predation is less frequently studied than competition as an organizing mechanism in communities. The power of predation to organize communities has been demonstrated by Paine (1966, 1969, and see Spight 1967), Murdoch (1969), and Connell (1961b) in marine communities; by Hutchinson (1961), Brooks and Dodson (1965), Brooks (1968), and Maguire, Belk, and Wells (1968) in freshwater communities; and suggested by Hairston, Smith, and Slobodkin (1960) in terrestrial communities.

\section{Methods}

The second experiment manipulated the trophic levels adjacent to the secondary carnivore level occupied by the Maculatum group. In some years Ambystoma tigrinum larvae feed almost exclusively on smaller amphibian larvae. On June 20, 1968, 16 A. tigrinum larvae were caught in the Southwest Woods Pond on the George Reserve. Their snoutvent lengths ranged from 39 to $57 \mathrm{~mm}$. A total of nine Rana sylvatica and seven Ambystoma tadpoles were found in 13 of the stomachs. The other three stomachs contained odonate nymphs, culicid larvae and pupae, Chaoborus larvae, and dytiscid larvae. There is no a priori reason to predict ecological interactions between $R$. sylvatica tadpoles and the Maculatum group ( $A$. laterale, $A$. tremblayi, and $A$. maculatum) except indirectly through the complex food web (Fig. 3).

A system of 16 eggs of each species in the Maculatum group was the object of a $2 \times 2$ factorial experiment. The four combinations of $A$. tigrinum $(0$ or 5) and $R$. sylvatica (0 or 300) were introduced on May 2-3, 1970, into pens that were randomized within the blocks of the competition experiment. This randomization permitted the generalizations of one experiment to apply to the other. All eggs were from matings between animals from the Large West Woods Pond on the George Reserve, which contains populations of all five species. All of the A. tigrinum 
TABLE 11. Effects of Ambystoma tigrinum and Rana sylvatica on the Maculatum group: data summary

\begin{tabular}{|c|c|c|c|c|c|c|c|}
\hline \multirow[b]{2}{*}{ Species } & \multirow{2}{*}{$\begin{array}{l}\text { Initial density } \\
\text { per pen } \\
\text { Rana sylvatica }\end{array}$} & \multicolumn{2}{|c|}{$\begin{array}{l}\text { Percentage } \\
\text { survivorship }\end{array}$} & \multicolumn{2}{|c|}{$\begin{array}{l}\text { Mean larval } \\
\text { period (days) }\end{array}$} & \multicolumn{2}{|c|}{$\begin{array}{l}\text { Mean body } \\
\text { weight }(\mathrm{g})\end{array}$} \\
\hline & & $\begin{array}{c}\text { Density of } \\
0\end{array}$ & A. tigrinum & $\begin{array}{c}\text { Density of } \\
0\end{array}$ & A. tigrinum & $\begin{array}{c}\text { Density of } \\
0\end{array}$ & A. tigrinum \\
\hline \multirow{2}{*}{ A. laterale } & 0 & $69 \%$ & $59 \%$ & $94(22)$ & $76(19)$ & 0.814 & 0.661 \\
\hline & 300 & $59 \%$ & $3 \%$ & $98(19)$ & 126 & 0.746 & 0.793 \\
\hline \multirow{2}{*}{ A. tremblayi } & 0 & $56 \%$ & $38 \%$ & $74(18)$ & $74(12)$ & 0.826 & 0.771 \\
\hline & 300 & $38 \%$ & $3 \%$ & $93(12)$ & 92 (1) & 0.773 & 1.403 \\
\hline \multirow{2}{*}{ A. maculatum } & 0 & $50 \%$ & $28 \%$ & 77 (16) & $86 \quad(9)$ & 1.086 & 1.061 \\
\hline & 300 & $72 \%$ & $22 \%$ & $110(23)$ & $107 \quad(7)$ & 0.940 & 1.328 \\
\hline
\end{tabular}

*The number of survivors from both blocks is in parentheses; all species of the Maculatum group had an initial density of 16 hatchlings per pen.

\section{TEMPORARY POND FOOD WEB}

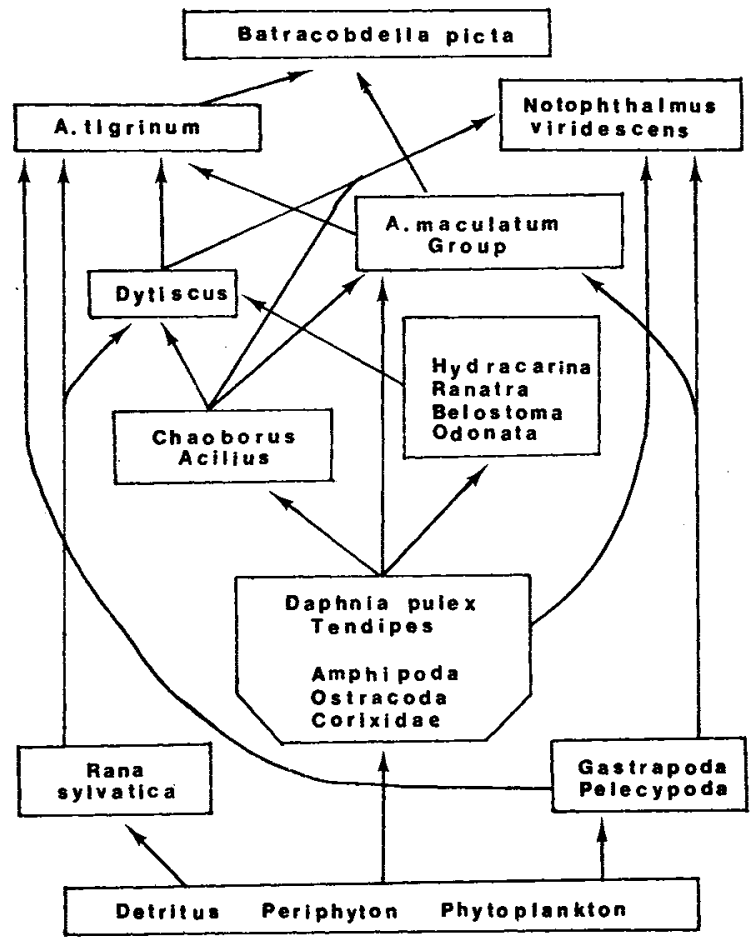

Fig. 3. Temporary pond food web. The feeding relationships are based on observations and collections in the Southwest Woods Pond, E. S. George Reserve.

eggs were from one female to avoid introducing an age structure into the small population of predators.

\section{Results}

All three species of the Maculatum group had a reduced survivorship $\left(F_{1,12}=6.066, P<0.05\right)$ when raised with $A$. tigrinum (Table 11 ). The presence of A. tigrinum did not change the length of the larval period of the Maculatum group, except as a com-
TABLE 12. Analysis of variance of body weight of the Maculatum group in communities with Ambystoma tigrinum and Rana sylvatica

\begin{tabular}{lrrrr}
\hline \multicolumn{1}{c}{ Source } & df & M.S. & \multicolumn{1}{c}{$F$} & \multicolumn{1}{c}{$F$} \\
\hline Species differences & 2 & 0.681 & 18.775 & $<0.001$ \\
Density of $A$. tigrinum & 1 & 0.253 & 6.985 & $<0.010$ \\
Density of $R$. sylvatica & 1 & 0.214 & 5.900 & $<0.050$ \\
Species X $A$. tigrinum & 2 & 0.180 & 2.966 & \\
Species X $R$. sylvatica & 2 & 0.075 & 2.075 & \\
A. tigrinum X $R$. sylvatica & 1 & 0.616 & 16.993 & $<0.001$ \\
Species X $A$. tigrinum X $R$. & & & & \\
$\quad$ sylvatica & 2 & 0.050 & 1.379 & \\
Error & 147 & 0.036 & & \\
\hline
\end{tabular}

ponent of the three-way interactions $\left(F_{2,147}=3.235\right.$, $P<0.05$ ). In the absence of $R$. sylvatica, $A$. tigrinum reduced the body size, but in the presence of $R$. sylvatica, $A$. tigrinum increased the body size of the Maculatum group (Tables 11 and 12). $R$. sylvatica significantly increased the larval period by as much as 50 days $\left(F_{1,147}=22.128, P<0.05\right)$.

A critical question is whether $A$. tigrinum acted as a predator or a competitor and if $R$. sylvatica had an effect on the Maculatum group in the absence of $A$. tigrinum. The reduced survivorship and the increased body size of the Maculatum group support the hypothesis of the predatory action of $A$. tigrinum. The analysis of body size suggests that $R$. sylvatica reduced the amount of food available to the $\mathrm{Macu}-$ latum group by cropping primary production, which is the food base of the invertebrates that are eaten by the salamanders (Fig. 3). $R$. sylvatica reduced the effect of predation by $A$. tigrinum. This result confirms the observation that $R$. sylvatica is the preferred food of $A$. tigrinum in natural ponds.

The causal mechanisms regulating the amphibian community are more evident in the analysis of the effects of the experiment on the $R$. sylvatica and $A$. tigrinum populations. The small sample sizes of $A$. tigrinum preclude statistical verification of conclu- 
TABle 13. Effects of the amphibian community on $\mathrm{Am}$ bystoma tigrinum

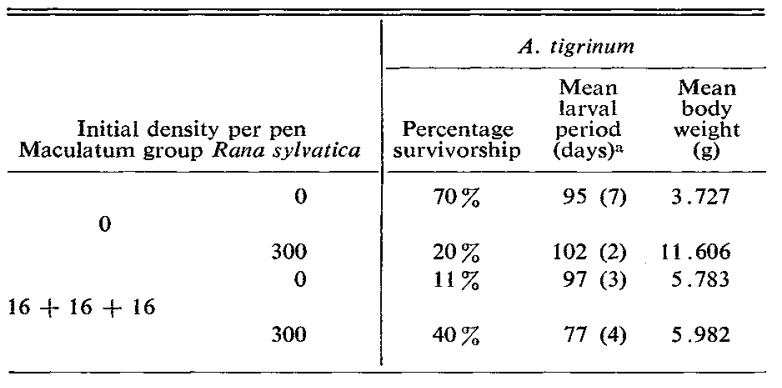

aSample size from both blocks is in parentheses.

TABLE 14. Effects of the amphibian community on Rana sylvatica

\begin{tabular}{|c|c|c|c|c|}
\hline & & \multicolumn{3}{|c|}{ Rana sylvatica } \\
\hline \multicolumn{2}{|c|}{$\begin{array}{l}\text { Initial density per pen } \\
\text { Maculatum group A. figrinum }\end{array}$} & $\begin{array}{l}\text { Percentage } \\
\text { survivorship }\end{array}$ & $\begin{array}{l}\text { Mean } \\
\text { larval } \\
\text { period } \\
\text { (days) }\end{array}$ & $\begin{array}{l}\text { Mean } \\
\text { body } \\
\text { weight } \\
\text { (g) }\end{array}$ \\
\hline 0 & 0 & $11.2 \%(67)$ & 53 & 0.194 \\
\hline \multirow{3}{*}{$16+16+16$} & 5 & $9.0 \%(54)$ & 51 & 0.186 \\
\hline & 0 & $15.8 \%(95)$ & 53 & 0.174 \\
\hline & 5 & $0.3 \%(3)$ & 54 & 0.245 \\
\hline
\end{tabular}

aSample size for both blocks is in parentheses.

sions; therefore, only trends in the data will be mentioned. All $A$. tigrinum larvae were from the same clutch so there was no age structure in the populations. In the absence of vertebrate prey, many small A. tigrinum evenly divided the invertebrate resources (Table 13). If $R$. sylvatica was available, A. tigrinum had a low survivorship, long larval period, and a large body size. A few larvae probably got an initial growth advantage and were able to exploit the $R$. sylvatica population. $A$. tigrinum had a similar response to the Maculatum group. When both prey types were available, $A$. tigrinum had a very short larval period and a relatively high survivorship.

Neither $A$. tigrinum nor the Maculatum group had a significant effect on the survivorship or the length of the larval period of $R$. sylvatica tadpoles because of the great variation between replicates (Table 14). The mean body size of $R$. sylvatica was significantly affected by $A$. tigrinum, both as a main effect $\left(F_{1,215}=4.763, P<0.05\right)$ and in its interaction with the Maculatum group $\left(F_{1,215}=7.523, P<\right.$ 0.01 ). The mean body size of $R$. sylvatica was reduced if either $A$. tigrinum or the Maculatum group was added to the system. However, $R$. sylvatica increased in body size and reduced its survivorship if both were added. In the absence of $A$. tigrinum, the effect of the Maculatum group was to increase the survivorship, but decrease the body size, of $R$. sylvatica. The total biomass of frogs increased from 13 to $16.5 \mathrm{~g}$ wet-weight. This suggests that the salaman- ders were preying on invertebrate herbivores (corixids, cladocerans, gastropods, etc.; see Fig. 3), which compete with $R$. sylvatica for food. Ambystoma tigrinum reduced the total biomass of $R$. sylvatica, probably by predation. In the presence of the Maculatum group, $A$. tigrinum increased its predation on $R$. sylvatica because of competition for invertebrate prey with the smaller species of Ambystoma. In conclusion, the five species of temporary pond amphibians have a complex relationship, which involves a mixture of competition and predation within and between preconceived "trophic levels." The very similar larvae of the Maculatum group have complex competitive interactions. There is no convincing evidence for predation among this group. Ambystoma tigrinum is a predator on all members of the Maculatum group if there is an opportunity to acquire a size advantage early in the summer, perhaps by eating $R$. sylvatica tadpoles. Ambystoma tigrinum preys on invertebrates and is a competitor of the Maculatum group if the opportunities to gain a size advantage do not occur. The role of $R$. sylvatica in the community as a herbivore and a food source for $A$. tigrinum also reduces the food available for the Maculatum complex.

This experiment suggests a possible network of biotic relationships that may regulate the entire community in temporary ponds. Briefly, primary productivity is consumed by either invertebrates or frog tadpoles. If predation is low, frogs may be food limited. Otherwise they are limited by $A$. tigrinum. The invertebrate consumers may be regulated by both salamander larvae and invertebrate predators. Beetle larvae (Dytiscus, Acilius, etc.) are abundant and may be as important as salamanders. The role of leech parasitism on amphibians is difficult to evaluate. Adult leeches (Batracobdella picta) feed on breeding salamanders in April. By late May leech broods are leaving their mother's ventral surface and attacking amphibian larvae. Very few dead larvae are found in the ponds, which suggests that leech parasitism may retard growth but is not fatal. This aspect of the larval ecology needs further study.

\section{Community Saturation}

The evidence of the ecology of colonization suggests that communities are ecologically saturated. Ecological saturation is operationally defined by introducing a foreign species into a community and asking if any of the native species are displaced by the invader. If the introduced species does not survive, saturation has not been demonstrated. The species may not have the physiological tolerances demanded by the physical environment. Thus, a test for ecological saturation must be accompanied by a demonstration of the ability of the species to survive in the new environment under reduced competition. 
TABLE 15. Competition between Ambystoma texanum and the Maculatum group

\begin{tabular}{|c|c|c|c|c|c|c|c|c|}
\hline \multirow[t]{2}{*}{ Native species } & \multicolumn{2}{|c|}{ Number of survivors ${ }^{a}$} & \multicolumn{2}{|c|}{$\begin{array}{l}\text { Percentage } \\
\text { survivorship }\end{array}$} & \multicolumn{2}{|c|}{$\begin{array}{l}\text { Mean } \\
\text { larval period (days) }\end{array}$} & \multicolumn{2}{|c|}{$\begin{array}{c}\text { Mean } \\
\text { body weight (g) }\end{array}$} \\
\hline & $\begin{array}{l}\text { Density } \\
0\end{array}$ & $\begin{array}{c}\text { A. } \text { texanum }^{\mathrm{b}} \\
16\end{array}$ & $\begin{array}{c}\text { Density } \\
0\end{array}$ & $\begin{array}{c}\text { A. texanum } \\
16\end{array}$ & $\begin{array}{c}\text { Density } \\
0\end{array}$ & $\begin{array}{l}\text { A. texanum } \\
16\end{array}$ & $\begin{array}{c}\text { Density } \\
0\end{array}$ & $\begin{array}{l}\text { A. texanum } \\
16\end{array}$ \\
\hline $\begin{array}{l}\text { A. laterale } \\
\text { A. tremblayi } \\
\text { A. maculatum }\end{array}$ & $\begin{array}{l}22 \\
18 \\
16\end{array}$ & $\begin{array}{l}20 \\
12 \\
15\end{array}$ & $\begin{array}{l}69 \% \\
56 \% \\
50 \%\end{array}$ & $\begin{array}{l}63 \% \\
38 \% \\
47 \%\end{array}$ & $\begin{array}{l}94 \\
74 \\
77\end{array}$ & $\begin{array}{r}100 \\
85 \\
88\end{array}$ & $\begin{array}{l}0.814 \\
0.826 \\
1.086\end{array}$ & $\begin{array}{l}0.516 \\
0.595 \\
0.937\end{array}$ \\
\hline
\end{tabular}

¿Sample size from both blocks.

bTwo $A$. texanum survived with a mean larval period of 101 days and a mean body weight of $0.491 \mathrm{~g}$.

There are numerous examples of competitive displacements both planned and accidental. Elton (1958), Baker and Stebbins (1965), DeBach and Sundby (1963), and MacArthur and Wilson (1967) review this literature. Theoretical arguments are presented by MacArthur and Wilson (1967) and MacArthur and Levins (1967) and are applied by Orians and Horn (1969).

\section{Methods}

The final experiment added 16 hatchling Ambystoma texanum to a community of 16 hatchlings of each species in the Maculatum species-group ( $A$. laterale, $A$. tremblayi, and $A$. maculatum). A. texanum was also raised alone at an initial density of 16 to demonstrate its ability to survive in Burt Pond. The three treatments (Maculatum group alone, $A$. texanum alone, and $A$. texanum with the Maculatum group) were replicated and randomized with the other experiments. The four species are remarkably similar in size (Table 15).

Ambystoma texanum occurs locally in extreme southern Michigan (University of Michigan Museum of Zoology [UMMZ] collections) at the northern limit of its geographical range. The materials for this study were eggs from two females from a population about $32 \mathrm{~km}$ south of the Reserve in Scio Township, Washtenaw County. Ambystoma texanum have been collected from this locality since 1942 (UMMZ 95415). Ambystoma maculatum, $A$. laterale, and $A$. tremblayi also breed in this pond (Stevan Arnold, personal communication), but they have low densities.

\section{Results}

One of the pens with a population of $16 \mathrm{~A}$. texanum was damaged. No salamanders transformed in this pen. It is evident that $A$. texanum is physiologically able to live in Burt Pond because 7 of 16 larvae in the replicate pen survived to metamorphosis. Only two $A$. texanum survived when they were raised with the Maculatum group; both were in the same pen. The $A$. texanum from the mixed population had a smaller body size $(0.492$ vs. $0.610 \mathrm{~g}$, not significantly different, $P>0.05)$ and a longer larval
TABLE 16. Analysis of variance of body weights of the Maculatum group in competition with Ambystoma texanum

\begin{tabular}{lrrrr}
\hline \multicolumn{1}{c}{ Source } & df & M.S. & \multicolumn{1}{c}{$F$} & \multicolumn{1}{c}{$P$} \\
\hline Species differences & 2 & 1.175 & 40.930 & $<0.001$ \\
Density of A. texanum & 1 & 1.262 & 43.962 & $<0.001$ \\
Species X A. texanum & 2 & 0.049 & 1.709 & \\
Error & 96 & 0.029 & &
\end{tabular}

period (101 vs. 78 days, not significantly different, $P>0.05$ ) than the seven survivors from the singlespecies population.

In the presence of $A$. texanum each species in the Maculatum group had a reduced survivorship, but the variance between replicates was too great for the effect to be significant (Table 15). The presence of $A$. texanum caused a highly significant increase in the length of the larval period $\left(F_{2,96}=7.707\right.$, $P<0.001)$ and a highly significant reduction in the body weight at metamorphosis of the species in the Maculatum group (Table 16). There were no significant interactions between the species differences and the density of $A$. texanum, indicating that the addition of $A$. texanum to the community equally affected $A$. laterale, $\boldsymbol{A}$. tremblayi, and $\boldsymbol{A}$. maculatum.

In conclusion, $A$. texanum was able to encroach into the community, but it had a low performance with respect to all measures of competitive ability. If the initial densities of the native species had been higher, the introduction of $A$. texanum may not have been successful. This experiment emphasizes the extreme plasticity of the ecology of salamander larvae. The addition of a foreign species affected the whole community because of the complex interactions between the species and their differential ability to modify growth rates. The concept of a trophic level as a resource line that is divided among species into discrete "food niches" is too simplistic (MacArthur and Levins 1967, Colwell 1969). The resources are part of a complex food web with direct and indirect connections between species in the same trophic level (Fig. 3).

The ecological plasticity of species and the flexibility of the food web have been noted by field 
biologists, but not laboratory and theoretical ecologists. Crowell (1962) studied the niche expansion of three species of birds on Bermuda, where there is reduced competition from other species. Lack and Southern (1949) found a similar niche expansion in the birds of Tenerife. Lack (1969) has argued that the process of ecological segregation of species may be a lengthy process. He compared the tits of Europe and North America and concluded that the European fauna is more complex because of a longer period of evolution. The salamanders are a counter-example. Lack attributes complexity of the fauna to perfection of niche segregation. The salamander fauna is complex because of the uncertainty of the pond environment, which precludes extreme specialization. The annual variation and the transience of ponds in evolutionary time do not permit the full course of competition. The complexity of the present fauna is due to the presence of good years and good ponds for each species, rather than a highly refined partitioning of a constant set of resources.

\section{CONCLUSIONS}

The classical models of laboratory ecologists are inadequate for interpreting natural communities. The inadequacies of these models were discovered by evaluating their assumptions in a complex community of predaceous vertebrates living in a changing environment. The evaluation of several assumptions of the classical models will be summarized and guidelines for constructing suitable models will be outlined.

Models of ecological communities usually are systems of differential equations. Typically each equation describes the rate change of one species through time as a function of the densities of all the species in the community. In its most general form, the model of a three-species community would be a system of three simultaneous differential equations:

$$
\begin{aligned}
& \mathrm{d} N_{1} / \mathrm{d} t=N_{1} f_{1}\left(N_{1}, N_{2}, N_{3}\right) \\
& \mathrm{d} N_{2} / \mathrm{d} t=N_{2} f_{2}\left(N_{1}, N_{2}, N_{3}\right) \\
& \mathrm{d} N_{3} / \mathrm{d} t=N_{3} f_{3}\left(N_{1}, N_{2}, N_{3}\right)
\end{aligned}
$$

in which $f_{1}, f_{2}$, and $f_{3}$ are unspecified functions of the initial densities of each species in the community. The empirical definition of these functions has been the raison d'etre of most laboratory studies. Charles Elton, hardly a laboratory ecologist, proposed in a presidential address to the British Ecological Society (1949) that the specification of these functions should be the goal of all ecology: "The ultimate goal of an ecological survey I would suggest is: 'an attempt to discover the main dynamic relations between populations living on an area.'" Mathematically oriented workers have specified the form of the functions by intuitively reasonable arguments (Rescigno and Richardson 1965, Kerner 1957, Rescigno 1968, Coutlee and Jennrich 1968); other ecologists have used more empirical arguments (Lotka 1932, Volterra 1928, Gause and Witt 1935). The Lotka-Volterra formulation has been a useful model for laboratory ecologists (Gause 1934; Miller 1964, 1967; Vandermeer 1969), and has been used as a model for evolutionary arguments (MacArthur and Wilson 1967; Hairston, Tinkle, and Wilbur 1970). The form of the system of equations invented by Lotka (1932) in the form of the logistic equation

$$
\begin{aligned}
& \mathrm{d} N_{1} / \mathrm{d} t=\left[r_{1} N_{1}\left(K_{1}-N_{1}-\alpha_{12} N_{2}-\alpha_{13} N_{3}\right)\right] / K_{1} \\
& \mathrm{~d} N_{2} / \mathrm{d} t=\left[r_{2} N_{2}\left(K_{2}-N_{2}-\alpha_{21} N_{1}-\alpha_{23} N_{3}\right)\right] / K_{2} \\
& \mathrm{~d} N_{3} / \mathrm{d} t=\left[r_{3} N_{3}\left(K_{3}-N_{3}-\alpha_{31} N_{1}-\alpha_{32} N_{2}\right)\right] / K_{3}
\end{aligned}
$$

has been a popular and intuitively acceptable model (Gause 1934, Slobodkin 1962, Levins 1968).

This model has several implicit assumptions. All individuals in the population are considered ecologically equivalent to other individuals from the moment they enter the population until they leave by death or emigration (Slobodkin 1953). The omission of age structure with its differences in mortality, fecundity, and competitive ability has not been serious in applications of the model to laboratory systems of protozoa (Gause 1934, Vandermeer 1969). More complex systems such as flour beetle communities require more sophisticated models with components for age differences and stochastic processes. The Lotka-Volterra model also assumes that the effect of one individual on another is independent of density (Smith 1952, Slobodkin 1955). If the system of equations describing the behavior of the system near its equilibrium point contains density-dependent terms $\left(\alpha_{i j}\right.$ becomes some function of $\left.N_{i}\right)$, then the locus of points of no change in the rate of change of species $i$ in the $N_{1}, N_{2}, N_{3}$ space would not be a system of three planes, but a complex of curved surfaces perhaps with several mutual intersections, each defining possible equilibria of the system. The initial abundances of the species would determine the final outcome of the community.

Another assumption of the model is that the competing species have a linear, additive effect on the capacity of a species to increase. The form of the "drag" terms $(K-N) / K$ in the Lotka-Volterra equations assumes that the rate of increase, or decrease, of species $i$ is proportional to the remaining resources in the habitat as determined by the number of conspecifics $N_{i}$ and the number of each competing species, the $N_{j}$ 's, which are appropriately transformed by the set of coefficients, the $\alpha_{i j}$. The effect of each species is additive if each individual removes a constant share of the resources, thereby increasing the "environmental resistance" $(K-N)$ / $K$ by an amount that is independent of the other individuals in the community. The preceding assumption of linearity requires that the share is indepcadent 
of the density of species $i$; the additivity assumption requires that the share is independent of the species composition of the community. Mathematically, the additivity assumption neglects higher-order interactions, such as the $\beta$ 's in the following equations. A failure of the assumption means that the drag terms of the model must be modified to the form

$$
\begin{aligned}
& \left(K_{1}-N_{1}-\alpha_{12} N_{2}-\alpha_{13} N_{3}-\beta_{1 \cdot 23} N_{2} N_{3}\right) / K_{1} \\
& \left(K_{2}-N_{2}-\alpha_{21} N_{1}-\alpha_{23} N_{3}-\beta_{2 \cdot 13} N_{1} N_{3}\right) / K_{2} \\
& \left(K_{3}-N_{3}-\alpha_{31} N_{1}-\alpha_{32} N_{2}-\beta_{3} \cdot 12 N_{1} N_{2}\right) / K_{3}
\end{aligned}
$$

which is a nonlinear system of equations when it is set to zero to solve for the equilibrium densities. Such a nonlinear system does not have the analytical power of the first-order system derived from the Lotka-Volterra model (Vandermeer 1969).

This additivity assumption was originally a simplification, which has been supported by the one resource-one species law that (unlike the one geneone enzyme law of genetics) remains a tenet of ecological theory (Levin 1970). My study does not deny the competitive exclusion principle, which is the result of laboratory studies and field observations that two species cannot coexist indefinitely on the same resource. This study does emphasize the complexity of the food web, the role of environmental uncertainty, and the extreme plasticity of the species in the structure of communities. The $A$. texanum experiment demonstrated that a community with a high density of salamanders could accept another species, not by eliminating one of the native species, but by changing the growth curves of all the species. The laboratory ecologists would argue that species could be added to the system until each species specialized on a single prey species. At this point the addition of a new species would require the extinction of another. Soon this reasoning becomes a semantic argument over the definition of the concept of a resource in ecology. Is Daphnia a resource? Daphnia pulex? Penultimate instars of Daphnia pulex? Penultimate instars of Daphnia pulex in the top $10 \mathrm{~cm}$ of the pond?

If the effects of species are not additive, the analytical tool of adding species to the community until the determinant and all subdeterminants of the community matrix pass through zero is also a gross oversimplification, in spite of its aura of elegance (Levins 1968, Vandermeer 1970). Nonadditivity was certainly the rule in the salamander community, both within and between species. The concept of "predator switching" (Murdoch 1969) is a step in the direction of an operational concept of community saturation. This theory tries to predict when a predator will "switch" from one resource to another as the composition of the community changes.

One assumption of the classical models withstood examination. Environmental heterogeneity did not obscure the effects of competition or the differences between species. This was true temporally (1968 [Wilbur 1971a] and 1970) and spatially (the analysis of blocks). The endurance of this important assumption is assurance that natural communities are organized by biotic mechanisms and that field experimentation can be used to elucidate the principles of community structure.

The final assumption that will be considered is common to all community models. It requires that the rules of community organization are constant throughout the study period. For example, the carrying capacity $K$ must be constant with respect to the generation time of the species. Andrewartha and Birch (1954:661) claim that climatic fluctuations prevent insects from reaching steady-state populations that would be predicted by a model based on competitive interactions. The mosaic pattern of the environment may change the rules of community structure in space. This concept has not been exploited by ecologists except for the first steps of Levene (1953), Levins (1968), and Colwell (1969).

The validity of the Lotka-Volterra model as a description of salamander communities has several aspects. The experimental method used an inputoutput approach rather than the collection of timeseries data. The differential growth of the species, the succession of prey species during the summer, and the variance in the length of the larval period suggest that interaction coefficients will not be constant throughout the experiment. The prolonged period of metamorphosis complicates the analysis of timeseries data because the effective density is continually changing and the importance of time lags are unknown. My earlier study (Wilbur 1971a) also indicated that competition coefficients were densitydependent. The failure of an empirical model, which was based on a single species, suggested that the effect of competition cannot be modeled by a linear combination of first-order coefficients. For this reason, a statistical approach was used to identify the important components that affect the system. The factorial design tested for the effect of the density of each species but did not assume an ordinal relationship between density levels, as in the design of the empirical, regression model. If precise models of salamander communities are desired, simple, linear, additive effects of competing species must be replaced by density-dependent functions, and it must be recognized that coalitions between species may result in either increased or decreased amounts of overlap of the niches of competitors. Also, the interaction between measures of competitive ability must be considered as part of an integrated strategy for competition. If only qualitative statements about the community are desired some of these components may be omitted (Vandermeer 1969), but the price 
of such simplification can be determined only by knowing the behavior of the full model. The significance of interaction components when none of the main effects are significant warns against a simplistic approach to complex communities.

Most community models have described the rate of change of the number of individuals of each species through time. A few ecologists have substituted biomass for the number of individuals as a description of the state of a species. Each approach uses a single measure of the quantity of each species. A useful evolutionary description of the state of an amphibian species requires two variables: the number of individuals and their mean body weight. For example, compare the outcomes of $A$. laterale populations raised from initial densities of 32 and 64 without competition with other species. At the high density there are more survivors (mean 27.5 vs. 10.5) and more biomass (mean 35 vs. $20 \mathrm{~g}$ wet-weight) than from low-density populations, but the mean body weight was much less ( 0.63 vs. $0.94 \mathrm{~g}$ wetweight). The cohort of juveniles from the low-density population would probably have a higher survivorship and an earlier age of maturity, and therefore would contribute more offspring to future generations than the cohort from the high-density population. If this is so, the traditional measures of population fitness, population size, or biomass would be erroneous. A bivariate representation of the population size and mean body weight is a more cumbersome index of population fitness, but it is a correct measure because it is a summation of the fitness of individuals. This argument refutes the indices chosen by many population geneticists (Carson 1957, 1958, biomass; Ayala 1965, 1966, 1968, 1970, 1971, population size). This problem has been recognized, in another context, by demographers. Models of populations with age structure represent the state of the population by an age vector, which has the size of each age class as elements (Leslie 1945, 1948). A model of the dynamics of an amphibian population might take the form of operations on a vector of size distributions.

Although I have played the role of the devil's advocate, I strongly feel that the classical models should not be disregarded. They are a valuable heuristic construct, and in their failure they point to the important questions of ecology. Without the simplified models, field ecologists could do little more than continue to gather data that "might be interesting." Usually they are not.

\section{ACKNOWLEDGMENTS}

I am grateful to my doctoral committee (Charles F. Walker, Nelson G. Hairston, Donald W. Tinkle, and Frank B. Livingstone) for their critical discussion and encouragement of my dissertation, which is the source of this paper. Daniel A. Livingstone, John H. Vandermeer, and the ecology group at the University of Michigan contributed ideas and techniques.

I inherited some field enclosures from Warren $Y$. Brockelman and Paul A. DeBenedictis and profited from their experiences. Francis C. Evans permitted the full use of the E. S. George Reserve facilities and gave me encouragement and insight. Dorothy $\mathrm{S}$. Wilbur helped with the field work and typing. Kenneth Guire and the staff of the University of Michigan Statistical Research Laboratory offered advice and support, but any errors in judgment and computation are my responsibility.

I was supported by: 1967-68, E. S. George Scholarships; 1967-68, Research Assistantship, Museum of Zoology; 1968-71, National Science Foundation Graduate Fellowships; and 1970-71, Junior Fellowship, the University of Michigan Society of Fellows. The research assistantship and materials were funded by a National Science Foundation grant for research in systematic and evolutionary biology (GB 8212, N. G. Hairston, principal investigator) and by the $E$. S. George Reserve Equipment Fund.

\section{Literature Cited}

Allee, W. C., A. E. Emerson, O. Park, and K. P. Schmidt. 1949. Principles of animal ecology. Saunders, Philadelphia. 837 p.

Andrewartha, H. G., and L. C. Birch. 1954. The distribution and abundance of animals. Univ. Chicago Press, Chicago. 782 p.

Ayala, F. J. 1965. Relative fitness of populations of Drosophila serrata and Drosophila birchi. Genetics 51: 527-544.

1966. Dynamics of populations. I. Factors controlling population growth and population size in Drosophila serrata. Amer. Natur. 100: 333-344.

1968. Genotype, environment, and population numbers. Science 162: 1453-1459.

1970. Population fitness of geographic strains of Drosophila serrata as measures by interspecific competition. Evolution 24: 483-494.

- 1971. Competition between species: frequency dependence. Science 171: 820-823.

Bailey, N. T. J. 1952. Improvements in the interpretation of recapture data. J. Anim. Ecol. 21: 120-127.

Baker, H. G., and G. L. Stebbins. 1965. The genetics of colonizing species. Academic Press, New York. 588 p.

Barnett, V. D. 1962. The Monte Carlo solution of a competing species problem. Biometrics 49: 76-103.

Bartlett, M. S. 1947. The use of transformations. Biometrics 3: 39-52.

Bartlett, M. S., C. Gower, and P. H. Leslie. 1960. A comparison of theoretical and empirical results for some stochastic population models. Biometrika 47: $1-11$.

Botzler, R. G. 1967. The incidence of Listeria monocytogenes, Pasteurella pseudoturberculosis, and Yersinia enterocolitica in frogs and turtles of the Edwin $S$. George Reserve. Masters Wildl. Manage. Thesis. Univ. Mich. 70 p.

Brockelman, W. Y. 1969. An analysis of density effects and predation in Bufo americanus tadpoles. Ecology 50: $632-644$.

Brooks, J. L. 1968. The effect of prey size selection by lake planktivores. Syst. Zool. 17: 272-291.

Brooks, J. L., and S. I. Dodson. 1965. Predation, body size, and composition of plankton. Science 150: 28 35 . 
Cantrall, I. J. 1943. The ecology of the Orthoptera and the Dermaptera of the George Reserve, Michigan. Misc. Pub. Mus. Zool. Univ. Mich. No. 54. 182 p.

Carson, H. L. 1957. Production of biomass as a measure of fitness of experimental populations of Drosophila. Genetics 42: 363-364.

- 1958 . Increase in fitness in experimental populations resulting from heterosis. Nat. Acad. Sci. (U.S.), Proc. 44: 1136-1141.

Chapman, R. N. 1928. The quantitative analysis of environmental factors. Ecology 9: 111-122.

Clements, F. E., and J. E. Weaver. 1924. Experimental vegetation. Carnegie Inst., Washington, D.C. 335 p.

Cody, M. L. 1968. On the methods of resource division in grassiand bird communities. Amer. Natur. 102: $107-147$.

Colwell, R. K. 1969. Ecological specialization and species diversity of tropical and temperate arthropods. Ph.D. Thesis. Univ. Mich. 79 p.

Connell, J. H. 1961a. The influence of interspecific competition and other factors on the distribution of the barnacle Chthamalus stellatus. Ecology 42: 710-723.

_ _ $1961 b$. Effect of competition, predation by Thias lapillus, and other factors on natural populations of the barnacle Balanus balanoides. Ecol. Monogr. 31: 61-104.

Cooper, A. W. 1958. Plant life-forms as indicators of microclimate. Ph.D. Thesis. Univ. Mich. 387 p.

Coutlee, E. L., and R. I. Jennrich. 1968. The relevance of logarithmic models for population interaction. Amer. Natur. 102: 307-321.

Crowell, K. L. 1962. Reduced interspecific competition among the birds of Bermuda. Ecology 43: 75-88.

Dawson, P. S., and I. M. Lerner. 1962. Genetic variation and indetermination in interspecific competition. Amer. Natur. 96: 379-380.

DeBach, P., and R. A. Sundby. 1963. Competitive displacement between ecological homologues. Hilgardia 35: $145-183$.

DeBenedictis, P. A. 1970. Interspecific competition between tadpoles of Rana pipiens and Rana sylvatica: an experimental field study. Ph.D. Thesis. Univ. Mich. $72 \mathrm{p}$.

Dice, L. R. 1952. Natural communities. Univ. Mich. Press, Ann Arbor. 547 p.

Eisenberg, R. M. 1966. The regulation of density in a natural population of the pond snail, Lymnaea elodes. Ecology 47: 889-906.

- 1970. The role of food in the regulation of the pond snail, Lymnaea elodes. Ecology 51: 680-684.

Elton, C. 1949. Population interspersion: an essay on animal community studies. J. Ecol. 37: 1-23.

1958. The ecology of invasions by animals and plants. Methuen, London. $181 \mathrm{p}$.

Frank, P. W. 1957. Coactions in laboratory populations of two species of Daphnia. Ecology 38: 510-519.

Gause, G. F. 1934. The struggle for existence. Williams and Wilkens, Baltimore. $163 \mathrm{p}$.

- 1936. The principles of biocoenology. Quart. Rev. Biol. 11: 320-336.

Gause, G. F., and A. A. Witt. 1935. Behavior of mixed populations and the problem of natural selection. Amer. Natur. 69: 596-609.

Hairston, N. G., J. D. Allen, R. K. Colwell, D. J. Futuyma, J. Howell, M. D. Lubin, J. Mathias, and J. H. Vandermeer. 1969. The relationship between species diversity and stability: an experimental approach with protozoa and bacteria. Ecology 49: 10911101.
Hairston, N. G., F. E. Smith, and L. B. Slobodkin. 1960. Community structure, population control, and compe:ition. Amer. Natur. 94: 421-425.

Hairston, N. G., D. W. Tinkle, and H. M. Wilbur. 1970. Natural selection and the parameters of population growth. J. Wildl. Manage. 34: 681-690.

Huffaker, C. R. 1958. Experimental studies on predation: dispersion factors and predator-prey oscillations. Hilgardia 27: 343-383.

Hutchinson, G. E. 1961. The paradox of the plankton. Amer. Natur. 95: 137-145.

Kerner, E. H. A. 1957. A statisical mechanics of interacting biological species. Bull. Math. Biophys. 19: 121-146.

Lack, D. 1969. Tit niches in two worlds: or homage to Evelyn Huichinson. Amer. Natur. 103: 43-49.

Lack, D., and H. N. Southern. 1949. Birds on Tenerife. Ibis 91: 607-626.

Leigh, E. 1965. On the relation between productivity, biomass, diversity, and stability of a community. Nat. Acad. Sci. (U.S.), Proc. 53: 777-783.

Lerner, I. M., and E. R. Demster. 1962. Indeterminism in interspecific competition. Nat. Acad. Sci. (U.S.), Proc. 48: 821-826.

Lerner, I. M., and F. K. Ho. 1961. Genotype and competitive ability of Tribolium species. Amer. Natur. 95: 329-343.

Leslie, P. H. 1945. On the use of matrices in certain population mathematics. Biometrika 33: 183-212.

- 1948. Some further notes on the use of matrices in population mathematics. Biometrika 35: 213-245. 1962. A stochastic model for two competing species of Tribolium and its application to some experimental data. Biometrika 49: 1-25.

Leslie, P. H., and J. C. Gower. 1958. The properties of a stochastic model for two competing species. Biometrica 45: 316-330.

Levene, H. 1953. Genetic equilibrium where more than one ecological niche is available. Amer. Natur. 87: 331-333.

Levin, S. A. 1970. Community equilibria and stability, and an extension of the competitive exclusion principle. Amer. Natur. 104: 413-423.

Levins, R. 1968. Evolution in changing environments. Princeton Univ. Press, Princeton. $120 \mathrm{p}$.

Lewontin, R. C. 1968. Introduction to the symposium, p. 1-4. In R. C. Lewontin [ed.] Population biology and evolution. Syracuse Univ. Press, Syracuse.

1969. The meaning of stability, p. 13-24. In G. M. Woodwell and H. H. Smith [ed.] Diversity and stability in ecological systems. Brookhaven Symp. Biol. No. 22.

Lotka, A. J. 1932. The growth of mixed populations: two species competing for a common food supply. J. Washington Acad. Sci. 22: 461-469.

MacArthur, R. H. 1955. Fluctuations of animal populations and a measure of community stability. Ecology 35: $533-536$.

MacArthur, R. H., and R. Levins. 1967. The limiting similarity, convergence, and divergence of coexisting species. Amer. Natur. 101: 377-385.

MacArthur, R. H., and E. O. Wilson. 1967. The theory of island biogeography. Princeton Univ. Press, Princeton. $203 \mathrm{p}$.

Maguire, B., Jr., D. Belk, and G. Wells. 1968. Control of community structure by mosquito larvae. Ecology 49: $207-210$.

Mertz, D. B. 1969. Age-distribution and abundance in 
populations of flour beetles. I. Experimental studies. Ecol. Monogr. 39: 1-31.

Mertz, D. B., and R. B. Davies. 1968. Cannibalism of the pupal stage by adult flour beetles: an experiment and stochastic model. Biometrics 24: 247-275.

Miller, R. S. 1964. Larval competition in Drosophila melanogaster and D. simulans. Ecology 45: 132-148. 1967. Pattern and process in competition. Adv. Ecol. Res. 4: 1-74.

Milne, A. 1961. Definition of competition among animals. Symp. Exp. Biol. 15: 44-61.

Mitchell, R. 1964. A study of sympatry in the water mite genus Arrenurus (Family Arrenuridae). Ecology 45: 546-558.

Murdoch, W. W. 1969. Switching in general predators: experiments on predator specificity and stability of prey populations. Ecol. Monogr. 39: 335-354.

1970. Population regulation and population inertia. Ecology 51: 497-502.

Nicholson, A. J. 1954. An outline of the dynamics of animal populations. Aust. J. Zool. 2: 9-65.

Nivin, B. S. 1967. The stochastic simulation of Tribolium populations. Physiol. Zool. 40: 67-82.

Odum, E. P. 1959. Fundamentals of ecology. 2nd ed Saunders, Philadelphia. 546. p.

-1962. Relationship between structure and function in the ecosystem. Jap. J. Ecol. 12: 108-118.

Orians, G. H., and H. S. Horn. 1969. Overlap in foods and foraging of four species of blackbirds in the Potholes of central Washington. Ecology 50: 930-938.

Paine, R. T. 1966. Food web complexity and species diversity. Amer. Natur. 100: 65-75.

- 1969. The Pisaster-Tegula interaction: prey patches, predator food preference, and intertidal community structure. Ecology 50: 950-961.

Park, T. 1954. Competition: an experimental and statistical study, p. 175-195. In O. Kempthorne, T. A. Bancroft, J. L. Gowen, and J. L. Lush [ed.] Statistics and mathematics in biology. Univ. Iowa Press, Ames.

Park, T., P. H. Leslie, and D. B. Mertz. 1964. Genetic strains and competition in populations of Tribolium. Physiol. Zool. 37: 97-162.

Park, T., D. B. Mertz, W. Grodzinski, and T. Prus. 1965. Cannibalistic predation in populations of flour beetles. Physiol. Zool. 38: 289-321.

Patrick, R. 1968. The structure of diatom communities in similar ecological conditions. Amer. Natur. 102: $173-183$.

Pianka, E. R. 1966. Latitudinal gradients in species diversity: a review of concepts. Amer. Natur. 100: 3346.

Rescigno, A. 1968. The struggle for life: II. Three competitors. Bull. Math. Biophys. 30: 291-298.

Rescigno, A., and I. W. Richardson. 1965. On the competitive exclusion principle. Bull. Math. Biophys. 27: 85-89.

Rogers, J. S. 1942. The crane flies (Tipulidae) of the
George Reserve, Michigan. Misc. Pub. Mus. Zool. Univ. Mich. No. 53. 128 p.

St. Amant, J. 1970. The detection of regulation in animal populations. Ecology 51: 823-828.

Sawyer, R. T. 1968. Notes on the natural history of the leeches (Hirundinea) on the George Reserve, Michigan. Ohio J. Sci. 68: 226-228.

Slobodkin, L. B. 1953. An algebra of population growth. Ecology 34: 513-519.

- 1955. Conditions for population equilibrium. Ecology 36: $530-533$.

—_ 1962. Growth and regulation of animal populations. Holt, Rinehart and Winston, New York. 184 p.

Smith, F. E. 1952. Experimental methods in population dynamics: a critique. Ecology 33: 441-450.

Smith, P. W. 1957. An analysis of post-Wisconsin biogeography of the Prairie Peninsula Region based on distribution phenomena among terrestrial vertebrate populations. Ecology 38: 205-218.

Sokal, R. R., and I. Huber. 1963. Competition among genotypes in Tribolium casteneum at varying densities and gene frequencies (the sooty locus). Amer. Natur. 97: 169-184.

Spight, T. M. 1967. Species diversity: a comment on the role of the predator. Amer. Natur. 101: 467-474.

Taylor, N. W. 1968. A mathematical model for two Tribolium populations in competition. Ecology 49: 843848.

Tihen, J. A. 1958. Comments on the osteology and phylogeny of ambystomatid salamanders. Bull. Florida State Mus. 3: 1-50.

Tilley, S. G. 1968. Size-fecundity relationships and their evolutionary implications in five desmognathine salamanders. Evolution 22: 806-816.

Vandermeer, J. H. 1969. The competitive structure of communities: an experimental approach with protozoa. Ecology 50: 362-371.

1970. The community matrix and the number of species in a community. Amer. Natur. 104: 73-83.

Visher, S. S. 1954. Climatic atlas of the United States. Harvard Univ. Press, Cambridge.

Volterra, V. 1928. Variations and fuctuations of the number of individuals in animal species living together. Trans. by M. E. Wells, p. 409-448. In R. N. Chapman. 1931. Animal ecology. McGraw-Hill, New York.

Wilbur, H. M. 1971a. The ecological relationship of the salamander Abystoma laterale to its all-female, gynogenetic associate. Evolution 25: 168-179.

- $1971 \mathrm{~b}$. Competition, predation and the structure of the Ambystoma-Rana sylvatica community. Ph.D. Thesis. Univ. Mich. 142 p.

Young, F. N., and J. R. Zimmerman. 1956. Variations in temperature in small aquatic situations. Ecology 37: $609-611$.

Zumberg, J. H., and J. E. Potzer. 1955. Pollen profiles, radiocarbon dating, and geological chronology of the Lake Michigan Basin. Science 121: 309-311. 